\title{
Mixed Venous Blood Gases Are Superior to Arterial Blood Gases in Assessing Acid-Base Status and Oxygenation during Acute Cardiac Tamponade in Dogs
}

\author{
David W. Mathias, Philip S. Clifford, and H. Sidney Klopfenstein \\ Departments of Medicine, Anesthesiology, and Physiology Medical College of Wisconsin, Milwaukee, Wisconsin 53226; \\ and Departments of Medicine and Physiology, The Bowman Gray School of Medicine, \\ Wake Forest University, Winston-Salem, North Carolina 27103
}

\begin{abstract}
Recent reports using anesthetized ventilator-dependent animal models, have suggested that in certain shock states, a disparity exists between arterial and mixed venous blood gases with regard to acid-base status and oxygenation. In a chronically instrumented unanesthetized canine model of acute cardiac tamponade breathing room air, we studied the effect of a graded decline in cardiac output on arterial and mixed venous $\mathrm{pH}, \mathrm{PCO}_{2}$, and $\mathrm{PO}_{2}$. Cardiac tamponade resulted in a profound arterial respiratory alkalosis, whereas mixed venous $\mathrm{pH}$, $\mathrm{PCO}_{2}$, and calculated serum bicarbonate levels remained relatively unchanged. As intrapericardial pressure increased and cardiac output declined, the difference between arterial and mixed venous $\mathrm{PCO}_{2}$ progressively increased. Further, whereas arterial oxygenation improved as cardiac output declined, mixed venous oxygenation steadily worsened. This disparity began early in cardiac tamponade (reductions in cardiac output of $20-40 \%$ ) long before arterial blood pressure began to fall and progressively worsened as hemodynamic deterioration and lactic acidosis developed. Our findings are consistent with the hypothesis that a reduction in blood flow, resulting in decreased $\mathrm{CO}_{2}$ delivery to the lungs, is the primary mechanism responsible for the difference in $\mathrm{pH}$ and $\mathrm{PCO}_{2}$ observed between arterial and mixed venous blood. In this conscious, spontaneously breathing animal model, mixed venous blood gases thus are superior to arterial blood gases in assessing acid-base status and oxygenation, even early in acute cardiac tamponade when the decline in cardiac output is in the range of 20 to $40 \%$ and arterial blood pressure has not changed significantly.
\end{abstract}

\section{Introduction}

The clinical use of arterial blood gases to assess acid-base status and oxygenation during shock states is a time-honored tradition. Recent reports, using anesthetized ventilator-dependent animal models, have suggested that in certain shock states, a disparity exists between arterial and mixed venous (pulmonary arterial) blood gases. In a porcine preparation of cardiac arrest, and in patients successfully resuscitated from cardiac arrest, Grundler and Weil $(1,2)$ demonstrated that there was a marked paradox of venous acidemia and hypercapnia with arterial alkalemia and hypocapnia. Halmagyi et al. (3) and

Address reprint requests to Dr. H. Sidney Klopfenstein, Cardiology Division, The Bowman Gray School of Medicine, 300 South Hawthorne Road, Winston-Salem, NC 27103. 1988.

Received for publication 6 April 1987 and in revised form 1 March

J. Clin. Invest.

(c) The American Society for Clinical Investigation, Inc.

$0021-9738 / 88 / 09 / 0833 / 06 \$ 2.00$

Volume 82, September 1988, 833-838
Paluch et al. (4) have also demonstrated selective mixed venous hypercarbia in anesthetized ventilator-dependent canine models of hemorrhagic hypotension and endotoxemia. This paradox was felt to result from a decreased clearance of carbon dioxide from the lungs when pulmonary blood flow was reduced. This is an important concept, because if it is true of reduced cardiac output states in spontaneously breathing conscious individuals, our current approach to the diagnosis and treatment of disorders of acid-base balance and oxygenation in these clinical situations is also incorrect.

Since these past studies have been limited to a narrow spectrum of clinical shock states and have been confounded by the use of anesthetized, ventilator-dependent models (5-9), we chose a chronically prepared unanesthetized canine model of graded cardiac tamponade, to test the hypothesis that, as cardiac output progressively declines, a disparity develops between arterial and mixed venous blood gases with regard to acid-base status and oxygenation.

\section{Methods}

Five mongrel dogs weighing $25.6-28.7 \mathrm{~kg}$ were screened for parasites, fasted overnight, and anesthetized with sodium pentobarbital (30 $\mathrm{mg} / \mathrm{kg}$ i.v. to effect). The dogs were then intubated and ventilated by a volume respirator (Harvard Apparatus Co. Inc., The Ealing Corp., S. Natick, MA) with air enriched with oxygen ( 6 liter $/ \mathrm{min})$. The electrocardiogram was monitored throughout the procedure and arterial blood gases were obtained hourly.

A left thoracotomy was performed in the fifth intercostal space using aseptic techniques. A polyvinyl catheter (Tygon, 0.05 in i.d.; Norton Co., Akron, $\mathrm{OH}$ ) was inserted into the left internal mammary artery and advanced to the aortic arch. After the position of the catheter was manually confirmed, it was secured and used to monitor arterial blood pressure and arterial blood gases throughout the procedure. A similar polyvinyl catheter was inserted into the right internal mammary vein, advanced to the right atrium, filled with a heparin solution, and sealed. A 3-4-cm incision was made in the pericardium overlying the proximal pulmonary artery and the left anterior descending coronary artery. An electromagnetic flowprobe was placed around the ascending aorta ([Howell Instrument Co., Camarillo, CA] used with a Narcomatic electromagnetic flowmeter, model RT-500; Narco Bio-Systems, Houston, TX). Two catheters (plastic Levin tube, $18 \mathrm{Fr}$; Davol Inc., Cranston, RI) were positioned in the pericardial space through separate purse-string sutures with their tips adjacent to the diaphragmatic surface of the left ventricle. A polyvinyl catheter was inserted into an extrapericardial branch of the left pulmonary artery through a purse-string suture and directed retrograde to the main pulmonary artery. After manual confirmation of its position, the catheter was secured, filled with a heparin solution, and sealed.

The pericardium was carefully sealed with a continuous locking suture. A chest tube was placed and all catheters were passed individually through the chest wall and tunneled subcutaneously to an area between the scapulae and exteriorized. The ribs were approximated with umbilical tape, and the muscle, subcutaneous tissue, and skin were closed in layers to provide an airtight seal. All catheters were flushed, filled with a heparin solution, and capped. The chest was 
evacuated by gentle suction on the chest tube, and the dog was fitted with a vest with a small pocket into which all catheters and transducer leads were placed. The pericardial cavity was emptied, $30 \mathrm{ml}$ of sterile saline was instilled, and the pericardial catheters were sealed. The animal was extubated and placed in an incubator overnight to recover. $1 \mathrm{mg} / \mathrm{kg}$ i.m. meperidine was given as needed for postoperative discomfort. After surgery, the animals were brought to the laboratory daily. The pericardial space was drained and $30 \mathrm{~cm}^{3}$ of normal saline was instilled. $500 \mathrm{mg}$ of cefazolin was given intravenously and all intravascular catheters were aspirated and refilled with a heparin solution.

4-5 d after surgery, the conscious dog was allowed to stand comfortably in a sling. The aortic, right atrial, pulmonary arterial, and pericardial catheters were attached directly to pressure transducers (P23Db; Statham Instrument Co., Hato Rey, PR). Respiratory rate was measured by recording the change in electrical resistance in a small mercury-filled silastic tube (Whitney gauge) placed around the thorax. The pericardial and pleural spaces were drained, and baseline data were recorded when the animal was comfortable and a steady-state situation had been achieved. When necessary, normal saline at body temperature was infused intravenously so that mean right atrial blood pressure in all animals was between 0 and $4 \mathrm{mmHg}$ during the baseline period. Cardiac tamponade was produced by the continuous infusion of $0.9 \%$ sterile saline at $37^{\circ} \mathrm{C}$ into the pericardial space at a rate of 20 $\mathrm{ml} / \mathrm{min}$ with an infusion pump (Masterflex; Cole-Parmer Instrument Co., Chicago, IL). The infusion was continued until decompensated cardiac tamponade resulted, defined as a decline in mean aortic blood pressure to $70 \%$ of the level present during the baseline period. The hemodynamic derangement was well tolerated and could be quickly reversed by rapid removal of the pericardial fluid.

During the infusion, hemodynamic data were continuously recorded by an FM tape recorder (A. R. Vetter Co., Rebersburg, PA). The same data were also recorded at $2-\mathrm{mmHg}$ increments in intrapericardial pressure on a strip chart recorder (model 2800; Gould Inc., Cleveland, $\mathrm{OH}$ ). At every 4-mmHg increase in intrapericardial pressure, $1 \mathrm{ml}$ of aortic and pulmonary arterial blood was withdrawn using heparinized tuberculin syringes (Becton, Dickinson \& Co., Oxnard, CA). All air bubbles were removed from the samples, and the samples were sealed and placed in an ice bath. Blood gas determinations were performed on both aortic and pulmonary arterial samples using a blood gas analyzer (Corning model 158; Corning Medical, Corning Glass Works, Medfield, MA). The hematocrit was measured in both the arterial and mixed venous samples using capillary tubes (Lancer Div., Sherwood Medical Industries, Foster City, CA) spun for $3 \mathrm{~min}$ in a micro-hematocrit centrifuge (Autocrit II; Clay Adams Div., Becton, Dickinson \& Co., Parsippany, NJ). Oxygen content was measured in arterial and mixed venous blood samples (Lex- $\mathrm{O}_{2}$-Con; Lexington Instruments, Waltham, MA). Percent saturation of hemoglobin was calculated by using the following formula: \%Sat $=(100)\left(\mathrm{O}_{2}\right.$ content $\left.-.003 \mathrm{PO}_{2}\right) / 1.39(\mathrm{Hct} / 3)$ (reference 10).
When decompensation was reached, hemodynamic data were recorded and blood samples were obtained. The pericardium was then evacuated by gentle suction on the pericardial catheters. The animal was allowed to recover for at least $1 \mathrm{~h}$ before recovery samples were drawn. A maximum of two experiments were performed in $1 \mathrm{~d}$ on a single animal, with sufficient time for recovery between experiments. All animals underwent four experiments over a 2-d period. The positions of all catheters were confirmed at autopsy, and the heart and aorta were removed with the flowprobe in place. Calibration of the flowprobe was performed using timed collections of normal saline (11).

In an additional group of three animals, decompensation was maintained for 20 min with infusions of fluid into the pericardium as needed to maintain mean arterial blood pressure at $<70 \%$ of baseline levels. 1-ml samples of aortic and pulmonary arterial blood were collected at 1, 3, 5, 8, 10, 15, and 20 min after reaching a decompensated state, and $15 \mathrm{~min}$ after removal of all pericardial fluid (recovery). Besides blood gas determinations, as previously described, mixed venous lactate levels were measured using a lactate analyzer (model 23L; Yellow Springs Instrument Co., Yellow Springs, $\mathrm{OH}$ ).

Hemodynamic data were transferred from an analogue tape to a digital computer (LSI 11/23; Digital Equipment Corp., Marlboro, MA) and sequential interactive programs were used to calculate cardiac output, all measured pressures, heart rate, and respiratory rate. A repeated measures analysis of variance with a single factor between subjects (arterial or mixed venous samples) and a single factor within subjects (level of intrapericardial pressure) was used to analyze the data (12). The Waller-Duncan multiple comparisons technique was used to compare individual means (13).

\section{Results}

20 episodes of acute cardiac tamponade were performed on five dogs (two episodes of tamponade in a single animal were eliminated due to suspected sepsis). Table I shows the mean hemodynamic data for all five dogs as cardiac tamponade progressed to decompensation. Decompensation occurred at a mean intrapericardial pressure of $18.4 \mathrm{mmHg}$. There was an increase in heart rate (from 135 to 186 beats $/ \mathrm{min} ; P<0.001$ ), respiratory rate (33-42/min; NS), and mean right atrial blood pressure $(4.8-16.6 \mathrm{mmHg} ; P<0.001)$ as cardiac tamponade progressed. Mean aortic blood pressure fell from 88 to 58 $\mathrm{mmHg}(P<0.001)$ and cardiac output declined from 3.0 to 1 liters/min $(P<0.001)$ as intrapericardial pressure increased.

The effects of cardiac tamponade on mixed venous (pulmonary arterial) blood gases are illustrated in Table II. There was no significant change in $\mathrm{pH}$ as decompensation was approached (7.40 to 7.39, $P=0.57$ ), although $\mathrm{PCO}_{2}$ ( 36.3 to 32.0

Table I. Hemodynamic Values during Acute Cardiac Tamponade

\begin{tabular}{|c|c|c|c|c|c|}
\hline IPP & HR & Respirations & $\mathbf{R A}$ & AoBP & Cardiac output \\
\hline$m m H g$ & beats/min & breaths/min & \multicolumn{2}{|c|}{$\mathrm{mmHg}$} & liter/min \\
\hline Baseline & $135 \pm 10$ & $33 \pm 13$ & $4.8 \pm 2.3$ & $88 \pm 4.0$ & $3.0 \pm 0.9$ \\
\hline 4 & $141 \pm 7$ & $28 \pm 5$ & $6.6 \pm 1.9$ & $90 \pm 1.0$ & $3.5 \pm 1.3$ \\
\hline 8 & $164 \pm 15^{*}$ & $30 \pm 4$ & $8.4 \pm 1.3^{*}$ & $90 \pm 10$ & $2.4 \pm 0.9 *$ \\
\hline 12 & $175 \pm 39 *$ & $36 \pm 4$ & $9.7 \pm 0.9^{*}$ & $89 \pm 12$ & $1.8 \pm 0.4^{*}$ \\
\hline 16 & $196 \pm 29^{*}$ & $41 \pm 15$ & $14.6 \pm 1.4^{*}$ & $79 \pm 8.0$ & $1.5 \pm 0.7^{*}$ \\
\hline \multicolumn{6}{|c|}{ Decompensation } \\
\hline (18.4) & $186 \pm 38^{*}$ & $42 \pm 19$ & $16.6 \pm 5.4^{*}$ & $58 \pm 5.0^{*}$ & $1.0 \pm 0.4^{*}$ \\
\hline
\end{tabular}

Mean $\pm \mathrm{SD} ;{ }^{*} P<0.05$ vs. baseline. Abbreviations: AoBP, aortic blood pressure; HR, heart rate; IPP, intrapericardial pressure; RA, right atrial blood pressure. 
Table II. Mixed Venous Blood Gases during Acute Cardiac Tamponade

\begin{tabular}{|c|c|c|c|c|c|c|}
\hline IPP & $\mathrm{pH}$ & $\mathrm{PCO}_{2}$ & $\mathrm{PO}_{2}$ & $\mathrm{HCO}_{3}$ & $\mathrm{O}_{2} \mathrm{SAT}$ & Het \\
\hline \multicolumn{2}{|l|}{$m m H g$} & \multicolumn{2}{|c|}{$m m H g$} & mmol/liter & \multicolumn{2}{|c|}{$\%$} \\
\hline Baseline & $7.40 \pm 0.03$ & $36.3 \pm 2.5$ & $32.3 \pm 3.5$ & $22.5 \pm 2.0$ & $61.8 \pm 6.3$ & $35.9 \pm 6.2$ \\
\hline 4 & $7.41 \pm 0.03$ & $33.7 \pm 3.2^{*}$ & $31.5 \pm 4.1$ & $21.3 \pm 3.0$ & $60.7 \pm 7.8$ & $33.0 \pm 5.3$ \\
\hline 8 & $7.43 \pm 0.03$ & $34.0 \pm 1.7^{*}$ & $30.1 \pm 2.6$ & $22.4 \pm 2.0$ & $59.0 \pm 4.6$ & $37.8 \pm 7.9$ \\
\hline 12 & $7.41 \pm 0.02$ & $33.3 \pm 4.3^{*}$ & $27.3 \pm 2.3^{*}$ & $21.1 \pm 2.7^{*}$ & $52.0 \pm 4.3^{*}$ & $42.9 \pm 5.5^{*}$ \\
\hline 16 & $7.41 \pm 0.03$ & $33.0 \pm 3.1^{*}$ & $25.3 \pm 3.4^{*}$ & $20.7 \pm 1.3^{*}$ & $46.8 \pm 7.7^{*}$ & $43.4 \pm 3.6^{*}$ \\
\hline \multicolumn{7}{|c|}{ Decompensation } \\
\hline$(18.4)$ & $7.39 \pm 0.09$ & $32.0 \pm 3.2^{*}$ & $20.9 \pm 2.0^{*}$ & $19.2 \pm 2.2^{*}$ & $35.4 \pm 5.6^{*}$ & $42.9 \pm 8.5^{*}$ \\
\hline
\end{tabular}

Mean \pm SD; ${ }^{*} P<0.05$ vs. baseline. Abbreviations: Hct, hematocrit; IPP, intrapericardial pressure; $\mathrm{O}_{2} \mathrm{SAT}, \mathrm{O}_{2}$ saturation.

$\mathrm{mmHg} ; P<0.05$ ) and calculated serum bicarbonate levels (22.5 to $19.2 \mathrm{mmol} /$ liter; $P<0.05$ ) showed small, but statistically significant reductions. Mixed venous $\mathrm{PO}_{2}$ and oxygen saturation, however, declined $\left(\mathrm{PO}_{2}\right.$, from 32.3 to $20.9 \mathrm{mmHg}$; $P<0.001 ; \mathrm{O}_{2}$ saturation, from 61.8 to $35.4 \% ; P<0.001$ ) as intrapericardial pressure increased and cardiac output fell. Mixed venous hematocrit increased during acute cardiac tamponade, reaching statistical significance at intrapericardial pressures of 12 and $16 \mathrm{mmHg}$, and decompensation (35.9 to $42.9 \% ; P<.001)$.

Arterial blood gases, likewise, showed significant changes during acute cardiac tamponade (Table III). Mean arterial pH increased from 7.43 to $7.59(P<0.001)$ with a decline in both $\mathrm{PCO}_{2}(29.1$ to $11.4 \mathrm{mmHg} ; P<0.001)$ and calculated serum bicarbonate levels ( 19.4 to $11.0 \mathrm{mmol} /$ liter; $P<0.001)$ indicating a profound respiratory alkalosis. Arterial $\mathrm{PO}_{2}$ (from 76.8 to $93.8 \mathrm{mmHg} ; P<0.001)$ and oxygen saturation $(95.6$ to $98.0 \% ; P<0.001$ ) actually increased as progressive hemodynamic deterioration occurred.

A striking disparity thus was present between arterial and mixed venous blood gases as intrapericardial pressure increased and cardiac output declined during cardiac tamponade. A statistically significant difference between the arterial and mixed venous $\mathrm{pH}$ when compared with their difference at baseline began at an intrapericardial pressure of $12 \mathrm{mmHg}$ and increased as decompensation was achieved (Fig. $1 A$ ). Likewise, $\mathrm{PCO}_{2}$ (Fig. $1 \mathrm{~B}$ ) and calculated serum bicarbonate levels (Fig. $1 C$ ) began to show a significant change (from the differences present at baseline) at an intrapericardial pressure of 12
$\mathrm{mmHg}$ when mean cardiac output was reduced by $40 \%$. Finally, a striking disparity was noted between arterial and mixed venous $\mathrm{PO}_{2}$ (Fig. $2 \mathrm{~A}$ ) and oxygen saturation (Fig. $2 \mathrm{~B}$ ). As intrapericardial pressure increased, arterial $\mathrm{PO}_{2}$ and oxygen saturation rose while mixed venous $\mathrm{PO}_{2}$ and oxygen saturation fell. A statistically significant difference between the arterial and mixed venous curves (when compared with their difference at baseline) began at an intrapericardial pressure of 8 $\mathrm{mmHg}$ when mean cardiac output was reduced by only $20 \%$.

To elicit metabolic acidosis, decompensated cardiac tamponade was continued for $20 \mathrm{~min}$ in three additional animals. The hemodynamic values obtained during extended decompensation and $15 \mathrm{~min}$ after removal of all pericardial fluid (recovery) are shown in Table IV. Mean aortic blood pressure remained at $<70 \%$ of baseline levels throughout the extended period of decompensation whereas cardiac output declined slightly (1.5 to 1.2 liters/min). Heart rate, right atrial blood pressure, and respiratory rate were essentially unchanged from the initiation of decompensation. Fig. 3 shows the effect of extended decompensation on arterial and mixed venous $\mathrm{pH}$ $(A)$, mixed venous lactate levels $(B)$, and $\mathrm{PCO}_{2}(C)$. Mixed venous $\mathrm{pH}$ declined from 7.39 to 7.29 , whereas arterial $\mathrm{pH}$ declined from 7.50 to 7.40. Throughout most of the experimental period, arterial alkalemia was present with mixed venous acidemia despite an increase in mixed venous lactate from $0.8 \mathrm{mmol} / \mathrm{liter}$ at baseline to $2.1 \mathrm{mmol} / \mathrm{liter}$ at decompensation and to $4.0 \mathrm{mmol} /$ liter after $20 \mathrm{~min}$ of hemodynamic decompensation. Mixed venous $\mathrm{PCO}_{2}$ rose from 32 to 35 $\mathrm{mmHg}$, whereas arterial $\mathrm{PCO}_{2}$ remained at $15 \mathrm{mmHg}$.

Table III. Arterial Blood Gases during Acute Cardiac Tamponade

\begin{tabular}{|c|c|c|c|c|c|c|}
\hline IPP & $\mathrm{pH}$ & $\mathrm{PCO}_{2}$ & $\mathrm{PO}_{2}$ & $\mathrm{HCO}_{3}$ & $\mathrm{O}_{2} \mathrm{SAT}$ & Het \\
\hline \multicolumn{2}{|l|}{$m m H g$} & \multicolumn{2}{|c|}{$m m H g$} & mmol/liter & \multicolumn{2}{|c|}{$\%$} \\
\hline Baseline & $7.43 \pm 0.04$ & $29.1 \pm 1.2$ & $76.8 \pm 5.8$ & $19.4 \pm 1.9$ & $95.6 \pm 1.1$ & $35.6 \pm 5.9$ \\
\hline 4 & $7.45 \pm 0.05$ & $28.0 \pm 2.0$ & $77.7 \pm 12.4$ & $19.3 \pm 1.7$ & $95.6 \pm 2.3$ & $32.1 \pm 5.2$ \\
\hline 8 & $7.49 \pm 0.04^{*}$ & $24.6 \pm 2.7^{*}$ & $80.2 \pm 12.6$ & $18.6 \pm 2.5^{*}$ & $96.3 \pm 2.1$ & $37.0 \pm 8.9$ \\
\hline 12 & $7.48 \pm 0.04^{*}$ & $22.4 \pm 4.3^{*}$ & $84.4 \pm 2.5^{*}$ & $16.7 \pm 2.5^{*}$ & $96.4 \pm 1.7$ & $42.1 \pm 7.3^{*}$ \\
\hline 16 & $7.51 \pm 0.06^{*}$ & $19.7 \pm 7.0^{*}$ & $95.9 \pm 14.1^{*}$ & $15.2 \pm 3.8^{*}$ & $97.7 \pm 1.3^{*}$ & $41.8 \pm 4.1^{*}$ \\
\hline \multicolumn{7}{|c|}{ Decompensation } \\
\hline$(18.4)$ & $7.59 \pm 0.10^{*}$ & $11.4 \pm 2.6^{*}$ & $93.8 \pm 9.2^{*}$ & $11.0 \pm 3.4^{*}$ & $98.0 \pm 0.4^{*}$ & $40.6 \pm 9.1^{*}$ \\
\hline
\end{tabular}

Mean \pm SD; ${ }^{*} P<0.05$ vs. baseline. Abbreviations: see Table II. 

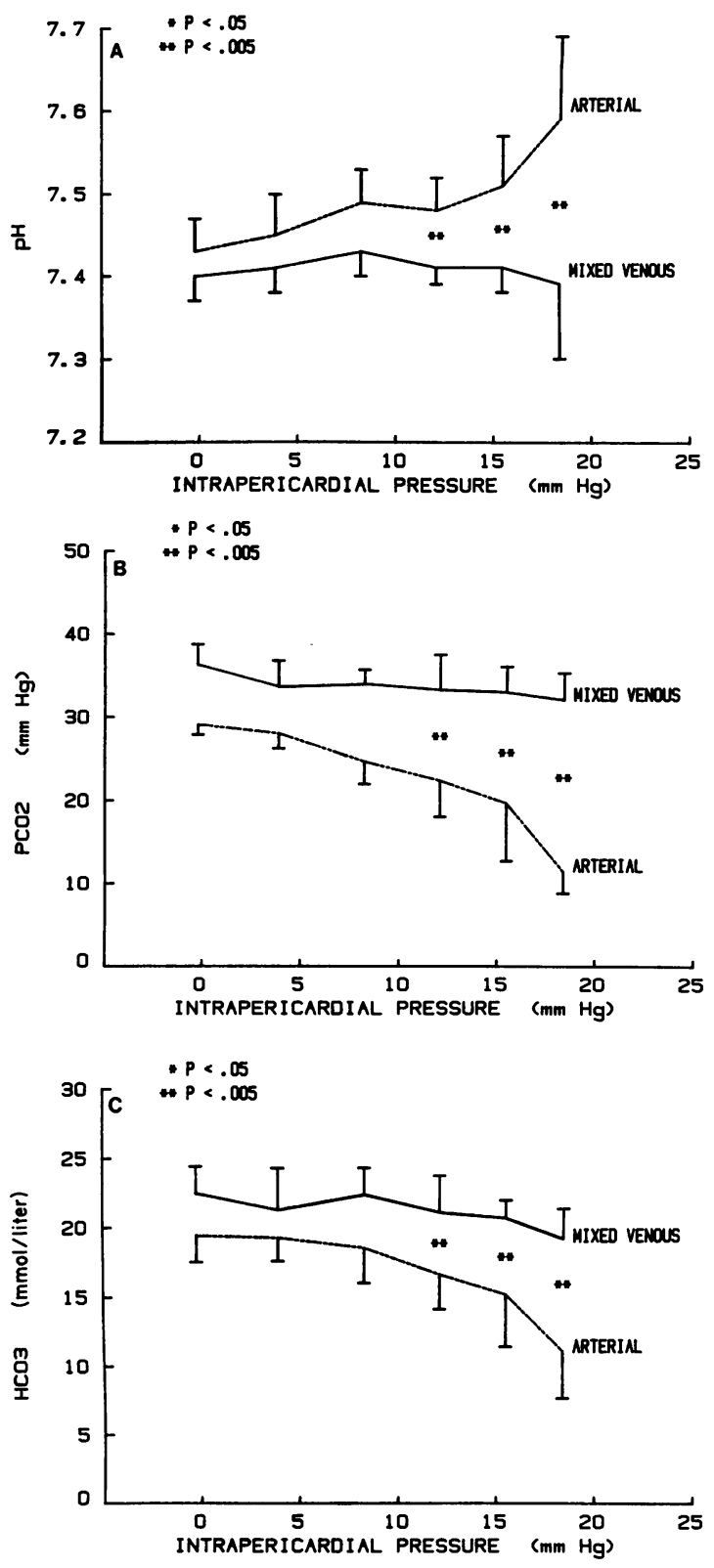

Figure 1. Effect of increasing intrapericardial pressure on arterial and mixed venous $(A) \mathrm{pH},(B) \mathrm{PCO}_{2}$, and $(C)$ calculated serum bicarbonate. Note that a statistically significant difference between the arterial and mixed venous curves (when compared with their difference at baseline) began at an intrapericardial pressure of $12 \mathrm{mmHg}$ and increased as decompensation was approached. (Mean \pm SEM.)

\section{Discussion}

Acute cardiac tamponade results in a progressive decline in cardiac output, ultimately leading to a shock state. In our chronic unanesthetized canine model, we found that increasing intrapericardial pressure (and the resulting decline in cardiac output) led to a progressive increase in the gradient between mixed venous and arterial $\mathrm{PCO}_{2}$, with no evidence of increased $\mathrm{CO}_{2}$ production. Acute cardiac tamponade produced a profound arterial respiratory alkalosis that achieved statistical significance before the development of hypotension when cardiac output had decreased by only $40 \%$ in these spontaneously breathing animals and progressively worsened as he-
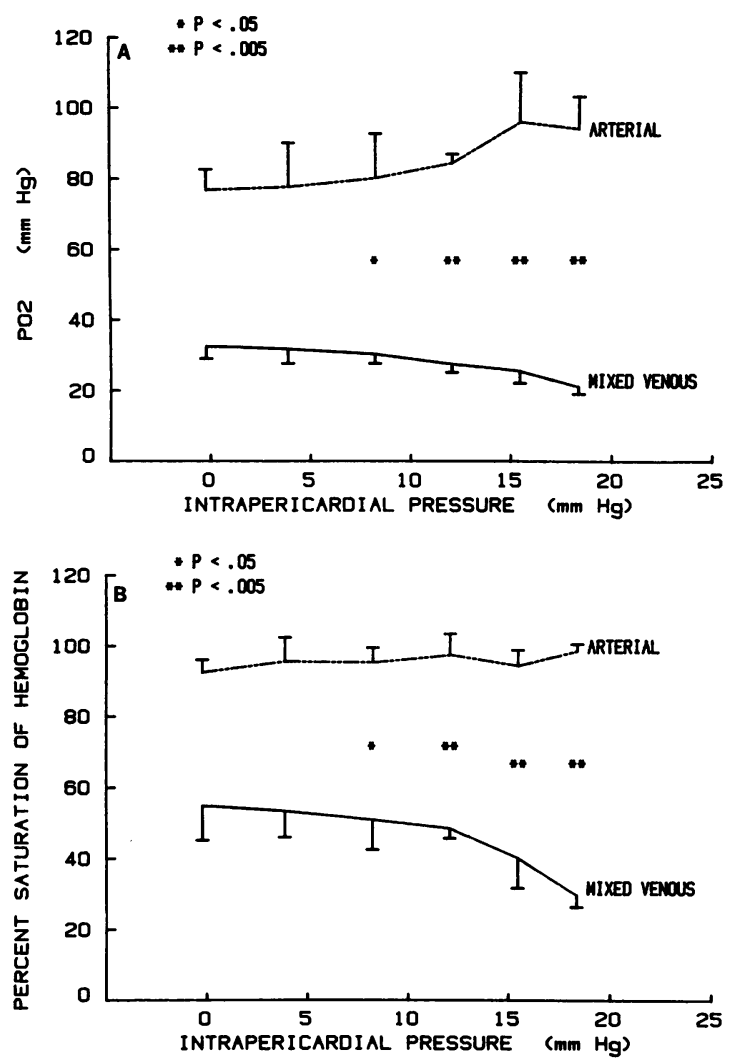

Figure 2. Effect of increasing intrapericardial pressure on arterial and mixed venous $(A) \mathrm{PO}_{2}$ and $(B)$ oxygen saturation. Note that once again a statistically significant difference between the arterial and mixed venous curves (when compared with their difference at baseline) began at an interpericardial pressure of $8 \mathrm{mmHg}$ and increased as decompensation was approached. (Mean \pm SEM.)

modynamic deterioration ensued. Mixed venous $\mathrm{pH}, \mathrm{PCO}_{2}$, and calculated bicarbonate levels, however, remained relatively constant throughout the experimental procedure.

The finding of arterial alkalemia and hypocapnia with mixed venous acidemia and hypercapnia has been reported in shock states. Grundler et al. (1), using an anesthetized ventilator-dependent porcine preparation exposed to cardiac arrest, demonstrated a marked venous acidemia and hypercapnia $\left(\mathrm{PCO}_{2}\right.$, from 45.2 to $54.2 \mathrm{mmHg} ; \mathrm{pH}, 7.41$ to 7.31$)$ in the presence of arterial alkalemia and hypocapnia $\left(\mathrm{PCO}_{2}\right.$, from 37.4 to $20.1 \mathrm{mmHg}$; $\mathrm{pH}, 7.46$ to 7.54 ) after successful resuscitation. Paluch et al. (4), using an anesthetized, mechanically ventilated canine model of endotoxemia, found a progressive increase in mixed venous $\mathrm{PCO}_{2}$ (from 41 to $66 \mathrm{mmHg}$ ) with a relatively constant arterial $\mathrm{PCO}_{2}(35$ to $45 \mathrm{mmHg}) 3 \mathrm{~h}$ after injection of endotoxin. Two studies of canine hemorrhagic shock $(3,14)$, using anesthetized ventilated dogs, have shown severe venous hypercapnia with reduced or normal arterial $\mathrm{PCO}_{2}$ levels. We chose to use a conscious unanesthetized canine model of graded cardiac tamponade breathing room air because the effect of incremental decrements in cardiac output, such as one would expect to see clinically, may be studied in this model before the development of and during graded shock in the absence of the confounding influences of anesthesia and artificial ventilation.

The mechanisms responsible for the disparity in acid-base 
Table IV. Hemodynamic Values during Extended Decompensation

\begin{tabular}{cccccc}
\hline IPP & HR & Respirations & RA & AoBP & Cardiac output \\
\hline$m m H g$ & beats/min & breaths/min & & mmHg & liter/min \\
Baseline & $113 \pm 14$ & $24 \pm 11$ & $6.5 \pm 3.4$ & $101 \pm 12$ & $2.9 \pm 0.1$ \\
4 & $111 \pm 12$ & $17 \pm 3$ & $7.0 \pm 2.8$ & $100 \pm 11$ & $2.9 \pm 0.2$ \\
8 & $113 \pm 13$ & $15 \pm 4$ & $7.5 \pm 2.1$ & $103 \pm 12$ & $2.9 \pm 0.1$ \\
12 & $153 \pm 64$ & $17 \pm 5$ & $9.9 \pm 2.0$ & $98 \pm 8$ & $2.4 \pm 1.0$ \\
Dct & $201 \pm 7$ & $33 \pm 9$ & $20.8 \pm 2.3$ & $67 \pm 7$ & $1.5 \pm 0.7$ \\
1 min & $208 \pm 3$ & $27 \pm 5$ & $18.5 \pm 0.9$ & $73 \pm 7$ & $1.5 \pm 0.4$ \\
3 min & $206 \pm 3$ & $27 \pm 10$ & $18.8 \pm 2.7$ & $70 \pm 2$ & $1.4 \pm 0.5$ \\
5 min & $201 \pm 8$ & $31 \pm 13$ & $19.9 \pm 2.2$ & $66 \pm 6$ & $1.3 \pm 0.6$ \\
8 min & $209 \pm 6$ & $31 \pm 0$ & $16.3 \pm 0.1$ & $69 \pm 4$ & $1.6 \pm 0.1$ \\
10 min & $199 \pm 12$ & $25 \pm 2$ & $20.6 \pm 3.0$ & $64 \pm 5$ & $1.2 \pm 0.6$ \\
15 min & $198 \pm 18$ & $27 \pm 8$ & $20.9 \pm 1.6$ & $66 \pm 4$ & $1.2 \pm 0.6$ \\
20 min & $196 \pm 20$ & $26 \pm 5$ & $21.1 \pm 5.2$ & $67 \pm 5$ & $1.2 \pm 0.6$ \\
Recovery & $130 \pm 19$ & $19 \pm 2$ & $8.0 \pm 3.7$ & $104 \pm 2$ & $3.3 \pm 0.1$ \\
\hline
\end{tabular}

Mean \pm SD. Abbreviations: see Table I. Dct, decompensation.

status between arterial and mixed venous blood gases are not well understood. The Fick equation states that $\mathrm{C} \overline{\mathrm{v}} \mathrm{CO}_{2}$ $=V \mathrm{CO}_{2} / Q+\mathrm{CaCO}_{2}$, where $\mathrm{C} \overline{\mathrm{v}} \mathrm{CO}_{2}$ is defined as mixed venous $\mathrm{CO}_{2}$ content, $V \mathrm{CO}_{2}$ is $\mathrm{CO}_{2}$ production by the tissues, $Q$ is tissue blood flow, and $\mathrm{CaCO}_{2}$ is arterial $\mathrm{CO}_{2}$ content. In contrast to findings obtained in the presence of anesthesia and mechanical ventilation, in our conscious spontaneously breathing animals, as cardiac output was gradually reduced by cardiac tamponade, we found a slight decrease in mixed venous $\mathrm{CO}_{2}$ content, a decrease in $\mathrm{CO}_{2}$ production by the tissues, and a striking decline in arterial $\mathrm{CO}_{2}$ content (hyperventilation). These changes began to occur at surprisingly small decrements in cardiac output before arterial blood pressure fell below baseline levels and persisted during extended decompensated cardiac tamponade as lactic acidemia developed.

As Farhi (15) pointed out, the blood's $\mathrm{CO}_{2}$ content is altered in two regions: the alveolar-arterial interface in the lungs, in which equilibration with arterial $\mathrm{PCO}_{2}$ occurs, and in the peripheral tissues of the body that equilibrate with the venous blood. With adequate cardiac output and venous return to the heart, there is sufficient communication between these two areas. However, as cardiac output and venous return to the heart decrease, these regions become increasingly isolated. Therefore, during cardiac tamponade, arterial blood gases reflect primarily alveolar-arterial exchange, whereas mixed venous blood gases are superior in assessing tissue acid-base status and oxygenation. Our findings are consistent with this hypothesis. The extreme hyperventilation we observed in our conscious model (in the absence of a significant change in respiratory rate) suggests that the ratio between alveolar ventilation and perfusion must become markedly elevated.

Graded acute cardiac tamponade resulted in a progressive increase in arterial and a decrease in mixed venous $\mathrm{PO}_{2}$ and oxygen saturation. Oxygen extraction by the tissues thus increased continuously. Further, a statistically significant difference between the arterial and mixed venous $\mathrm{PO}_{2}$ and oxygen saturation curves (when compared with their difference at baseline) began at an intrapericardial pressure of $8 \mathrm{mmHg}$ when mean cardiac output was reduced by only $20 \%$. A reduction in mixed venous $\mathrm{PO}_{2}$ as cardiac output declined has been previously reported (16-18) and forms the basis for the use of serial mixed venous oxygen determinations to assess the severity of various shock states. However, since cardiac output is equal to oxygen consumption divided by the difference in oxygen content between arterial and venous blood (19), for mixed venous oxygen levels to reflect changes in cardiac output, oxygen consumption and arterial oxygen content must remain relatively constant (20). In our model of acute cardiac tamponade, we have found neither of these assumptions to be valid (21).

The changes in arterial $\mathrm{pH}, \mathrm{PCO}_{2}$, and $\mathrm{PO}_{2}$ that resulted from an increase in intrapericardial pressure in our experiments would not be expected to cause hyperventilation. One may speculate that afferent input leading to hyperventilation may have resulted from stimulation of cardiac or pericardial receptors.

In conclusion, this study demonstrates that as cardiac output declines during graded acute cardiac tamponade in conscious dogs, a progressive disparity develops between arterial and mixed venous blood gases with regard to both acid-base status and oxygenation. This disparity begins early in cardiac tamponade (with reductions in cardiac output of 20 to $40 \%$ ) and progressively worsens as hemodynamic deterioration and lactic acidosis ensue. Our findings are consistent with the hypothesis that relative hyperventilation and decreased $\mathrm{CO}_{2}$ delivery to the lungs when pulmonary blood flow was reduced are the primary mechanisms responsible for the difference in $\mathrm{pH}$ and $\mathrm{PCO}_{2}$ observed between arterial and mixed venous blood in these conscious animals. Acute cardiac tamponade resulted in a rise in arterial $\mathrm{PO}_{2}$ and oxygen saturation, whereas mixed venous $\mathrm{PO}_{2}$ and oxygen saturation declined. During cardiac tamponade in this canine model, arterial blood gases thus primarily reflect alveolar-capillary exchange, whereas mixed venous blood gases are superior in assessing tissue acidbase status and oxygenation. 

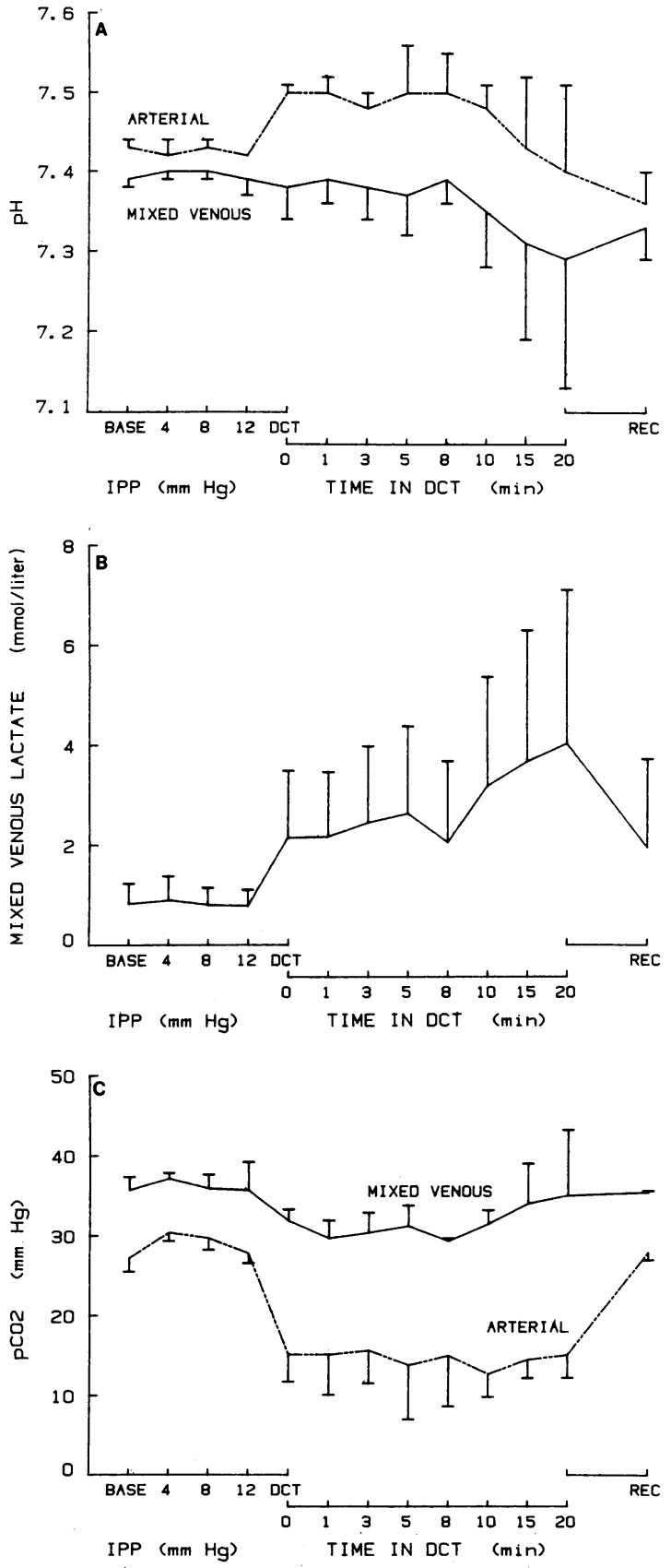

Figure 3. Effect of extended decompensation (DCT) on $(A)$ arterial and mixed venous $\mathrm{pH},(B)$ mixed venous lactate levels, and $(C)$ arterial and mixed venous $\mathrm{PCO}_{2}$. Note that as decompensation continues, mixed venous acidemia and lactic acidosis develop with arterial alkalosis. (Mean \pm SEM.)

\section{Acknowledgments}

We gratefully acknowledge James Roberts, Peter Czakanski, Charles Klopfenstein, and Donna Siegesmund, for their able assistance in performing these experiments, Jessica Provine for preparing the manuscript, and Raymond G. Hoffman for performing the statistical analysis.
Statistical analysis was supported in part by the General Clinical Research Center grant RR00058.

\section{References}

1. Grundler, W., M. H. Weil, and E. C. Rackow. 1986. Arteriovenous carbon dioxide and $\mathrm{pH}$ gradients during cardiac arrest. Circulation. 74:1071-1074.

2. Weil, M. H., E. C. Rackow, R. Trevino, W. Grundler, J. L. Falk, and M. I. Griffel. 1986. Difference in acid-base state between venous and arterial blood during cardiopulmonary resuscitation. $N$. Engl. J. Med. 315:153-156.

3. Halmagyi, D. F. J., M. Kennedy, and D. Varga. 1970. Hidden hypercapnia in hemorrhagic hypotension. Anesthesiology. 33:594601.

4. Paluch, T. A., E. Benjamin, J. S. Stein, and T. J. Iberti. 1985. Regional $\mathrm{CO}_{2}$ production in canine endotoxemia. Anesthesiology. 63(Suppl.):158a. (Abstr.)

5. Gennari, F. J. 1986. Letter. N. Engl. J. Med. 315:1616.

6. Barton, R. 1986. Letter. N. Engl. J. Med. 315:1616.

7. Benjamin, E., T. A. Paluch, D. R. Gentili, and T. J. Iberti. 1986. Letter. N. Engl. J. Med. 315:1616-1617.

8. Johnson, D. C., and D. M. Systrom. 1986. Letter. N. Engl. J. Med. 315:1617.

9. Chazan, J. A. 1986. Letter. N. Engl. J. Med. 315:1617.

10. Danek, S. J., J. P. Lynch, J. G. Weg, and D. R. Dantzker. 1980. The dependence of oxygen uptake on oxygen delivery in the adult respiratory distress syndrome. Am. Rev. Respir. Dis. 122:387-395.

11. Bergel, D. H., and U. Gessner. 1966. The electromagnetic flowmeter. In Methods in Medical Research. Vol. II. R. F. Rushmer, editor. Year Book Medical Publishers, Inc., Chicago, IL. 70-82.

12. Winer; B. 1971. Experimental Design. McGraw-Hill Book Co., New York. 514-603.

13. Meller, R. G. 1981. Simultaneous Statistical Inference. Springer-Verlag, New York. 257-259.

14. Benjamin, E., T. J. Iberti, S. S. Berger, D. R. Gentili, T. A. Paluch, and G. V. Gabrielson. 1986. Venous hypercarbia in canine hemorrhagic shock. Crit. Care Med. 14:429a. (Abstr.)

15. Farhi, L. E. 1965. Gas stores of the body. In The Handbook of Physiology. Vol. 1 (Respiration), section 3. W. O. Fenn and H. Rahn, editors. American Physiological Society, Washington, DC. 873-885.

16. Gore, J. M., and K. Sloan. 1984. Use of continuous monitoring of mixed venous saturation in the coronary care unit. Chest. 86:757761.

17. Birman, H., A. Haq, E. Hew, and A. Aberman. 1984. Continuous monitoring of mixed venous oxygen saturation in hemodynamically unstable patients. Chest. 86:753-756.

18. Fahey, P. J., K. Harris, and C. Vanderwarf. 1984. Clinical experience with continuous monitoring of mixed venous oxygen saturation in respiratory failure. Chest. 86:748-752.

19. Jamieson, W. R. E., K. W. Turnbull, A. J. Larrieu, W. A. Dodds, J. C. Allison, and G. F. O. Tyers. 1982. Continuous monitoring of mixed venous oxygen saturation in cardiac surgery. Can. J. Surg. 25:538-543.

20. Tenney, S. H. 1974. A theoretical analysis of the relationship between venous blood and mean tissue oxygen pressures. Respir. Physiol. 20:283-296.

21. Mathias, D. W., J. Roberts, P. Czakanski, C. Klopfenstein, and H. S. Klopfenstein. 1987. Oxygen consumption declines during acute cardiac tamponade in unanesthetized dogs. Clin. Res. 35:303a. (Abstr.) 